\title{
Composite arterial grafts versus conventional grafting for coronary artery bypass grafting
}

\author{
J. F. Légaré \\ K. J. Buth \\ J. A. Sullivan \\ G. M. Hirsch
}

From the Dalhousie University, Halifax, Nova Scotia, Canada.

Received for publication Jan 21, 2003; revisions received June 14, 2003; accepted for publication June 23, 2003

Address for reprints: Dr Gregory Hirsch, New Halifax Infirmary QEII HSC, 1796 Summer St, Rm 2269, Division of Cardiac Surgery, Halifax, Nova Scotia, Canada B3H 3A7 (E-mail: ghirsch@is.dal.ca).

J Thorac Cardiovasc Surg 2004;127:160-6 $0022-5223 / \$ 30.00$

Copyright $\odot 2004$ by The American Association for Thoracic Surgery

doi:10.1016/j.jtcvs.2003.06.016
Objectives: Composite arterial grafts for coronary artery bypass grafting surgery allow complete arterial revascularization but are limited by the inflow of a single internal thoracic artery supplying all the grafted vessels. We reviewed the safety of composite arterial grafts using either bilateral internal thoracic arteries or a single internal thoracic artery and radial artery.

Methods: From January 1999 to July 2002, 402 consecutive patients receiving composite grafts only were compared to a control group of patients $(n=542)$ undergoing coronary artery bypass grafting with internal thoracic artery and saphenous veins operated upon by the same surgeons. Two different statistical approaches were used to compare groups in this retrospective analysis. First, propensity score analysis with greedy matching technique was used to match patients from each group. Second, a multivariate analysis was performed looking at a combined patient outcome of death, intra-aortic balloon counterpulsation utilization, myocardial infarction, stroke, and prolonged ventilation on all patients in both groups.

Results: After matching by propensity score, the major clinical outcomes in composite arterial $(n=249)$ and control $(n=249)$ groups were found to be similar. The in-hospital mortality in the composite group was $1.2 \%$ as compared with $0.4 \%$ in matched patients $(P=.62)$. However, patients in the composite group were found to have a significantly longer pump time $(P<.0001)$, longer clamp time $(P<$ $.0001)$, increased incidence of prolonged mechanical ventilation $(12.8 \%$ vs $4.8 \% ; P$ $=.002)$, and higher incidence of combined morbidity outcome $(13.6 \%$ vs $6.4 \% ; P$ $=.007)$ as compared with matched patients. Multivariable analysis showed that composite arterial grafting was an independent predictor of the combined morbidity outcome with an odds ratio of $2.1(1.2-3.7)$.

Conclusions: These findings suggest that composite arterial grafting may be associated with an increase in risk-adjusted patient morbidity when compared with a conventional coronary artery bypass grafting group, although a mortality difference was not demonstrable.

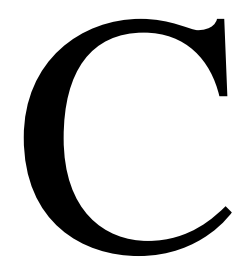

oronary artery bypass grafting (CABG) is a well-established therapy for patients with multivessel coronary artery disease, with excellent short- and medium-term results. ${ }^{1}$ There are concerns, however, about long-term results of vein grafts utilized for CABG. Fitzgibbon and colleagues ${ }^{2}$ in a prospective study of 1388 patients (many of whom underwent angiography early, at 1 year, 5 years, and up to 22.5 years after operation) have reported long-term vein graft patencies of $50 \%$. Graft occlusion can result in return of disabling angina, the need for rehospitalization, reintervention, and death. ${ }^{3}$ In contrast, it is well established that patency rates for left internal thoracic artery (ITA) grafts to the left anterior descending 
artery are excellent compared with saphenous vein grafts (SVGs), with patency rates at 10 years of $90 \%{ }^{3}$ Utilization of left ITA grafts has also been demonstrated to confer a survival benefit to patients having $\mathrm{CABG}^{4}$

Because of the excellent results with left ITA grafts it has been hypothesized that exclusive arterial revascularization without SVGs would result in improved long-term results following $\mathrm{CABG}^{4-6} \mathrm{In}$ support of this, there are numerous published series of patients undergoing CABG with complete arterial revascularization using a variety of arterial conduits (eg, radial artery, left ITA, right ITA, gastroepiploic) demonstrating feasibility and safety. ${ }^{7-11}$ This is particularly true after recent renewed interest in and demonstration of safety with radial artery conduits. ${ }^{9-12}$

To facilitate exclusive arterial revascularization, composite arterial grafting creating a $\mathrm{Y}$ or $\mathrm{T}$ graft from a pedicled ITA (left or right) has been proposed. ${ }^{711}$ Although the safety of this approach is supported by single-center case series with excellent survival, a direct comparison with conventional ITA and SVG cases has yet to be made. The objective of the present study was to evaluate the safety of composite arterial grafts by comparing outcomes to a control group of patients where left ITA and SVG were utilized, using propensity score and multivariable analysis.

\section{Materials and Methods \\ Patients}

From January 1999 to July 2002, 402 consecutive patients undergoing coronary revascularization with exclusively composite arterial grafts (no aortic anastomoses) utilizing either 2 ITAs or 1 ITA in combination with a radial artery were identified. During the same study period 542 consecutive patients undergoing CABG that utilized the left ITA in combination with SVGs anastomosed proximally to the aorta were identified. All surgeries were performed by a group of 4 surgeons contributing to both composite and control groups. Patients with preoperative intra-aortic balloon counterpulsation (IABP) were excluded.

Indications for CABG surgery were based on a weekly peerreview process, involving cardiologist, cardiac surgeons, and cardiac radiologists. Individual patients were placed on a specific wait list according to urgency of procedure. Cardiopulmonary bypass (CPB) for coronary bypass surgery at our institution was performed in a standardized fashion. Body temperature during the procedure was allowed to drift to approximately $32^{\circ} \mathrm{C}$. Intermittent cold blood cardioplegic solution was delivered antegrade via the aortic root unless otherwise indicated. The choice of conduits and/or construction of composite grafts was based on surgeon preferences rather than fixed criteria such as territory to graft, degree of target vessel stenosis, vessel size, or flow. Arterial conduits were harvested with minimal trauma (nonskeletonized ITA) and all treated with either a papaverine solution or nitroglycerine/calcium channel blocker (verapamil) solution prior to use. The composite anastomosis, in the majority of patients, was per- formed under cardioplegic arrest after all distal anastomoses had been completed. Patients who had beating heart surgery (OPCAB) were included in this analysis and this group consisted of 97 patients (10.3\%).

\section{Postoperative Management}

All patients received intravenous nitroglycerin $(0.1-8 \mathrm{ug} / \mathrm{kg} / \mathrm{min})$ infusions for the first 24 hours unless hypotensive (systolic blood pressure $<90 \mathrm{~mm} \mathrm{Hg}$ ). Oral nifedipine (Adalat $10 \mathrm{mg}$ by mouth 4 times a day or Adalat XL $30 \mathrm{mg}$ daily; Bayer, Inc, Toronto, Ontario, Canada) was prescribed for all patients receiving a radial artery beginning on day 1 postoperatively for a period of 3 to 6 months. Other routine medications included daily aspirin and resumption of cholesterol-lowering agents and $\beta$-blockers.

\section{Data Collection}

Perioperative patient variables were collected by 3 full-time research assistants and maintained in the Maritime Heart Center Cardiac Surgery Database. This has been a standard practice at this institution for all cardiac surgical cases since 1995 with regular data validation. An elective case was defined as a patient waiting at home prior to the procedure; in-house cases were defined as hospitalized patients requiring surgery; urgent cases were defined as cases where surgery were required to be performed within 24 hours to prevent further clinical deterioration; and emergency/ emergency salvage cases were those patients who required an immediate operation. Twelve-lead electrocardiogram was recorded before the operation, at 2 hours after surgery, and then when clinically indicated. Electrocardiographic diagnosis criteria for perioperative myocardial infarction (MI) were new Q-wave (0.04 $\mathrm{ms}$ ) in at least 2 leads or electrocardiographic ST changes in association with significant creatine kinase MB enzyme release.

\section{Data Analysis}

All analyses were performed with the Statistical Analysis Systems software package (SAS, Release 8.2, Cary, NC). Descriptive statistics included continuous and discrete variables, which were analyzed accordingly with an unpaired $t$ test, Wilcoxon rank sum test, chi-square test, and Fisher exact test.

A propensity analysis was performed modeling probability of receiving a composite arterial graft. Briefly, a nonparsimonious multivariable logistic regression model using clinically relevant variables was generated to compute a propensity score for each patient (Appendix). All clinically relevant variables were included into the model. The propensity score (or probability of receiving a composite graft) was then used to obtain a 1-to-1 match of composite cases with CABG controls (left ITA + SVG) by a "greedy matching" technique. ${ }^{13}$ Outcomes were compared between these matched groups.

Finally, a multivariable logistic regression model was used to analyze combined adverse outcomes. The fully adjusted model included 24 patient variables, as well as the type of grafting performed (composite versus control), individual surgeons, and propensity score. In an additional regression analysis we included time and experience variables as model variables. The time and experience variables included were: composite early experience, ITA + SVG early experience, composite late experience, ITA + 
TABLE 1. Patient characteristics of composite arterial grafts versus LITA + SV, in 944 unmatched cases

\begin{tabular}{|c|c|c|c|}
\hline $\begin{array}{l}\text { Preoperative patient } \\
\text { characteristic }\end{array}$ & $\begin{array}{l}\text { Composite graft } \\
\text { (n = 402), \% }\end{array}$ & $\begin{array}{c}\text { LITA + SV } \\
(n=542), \%\end{array}$ & $P$ value \\
\hline \multicolumn{4}{|l|}{ Age } \\
\hline$<60$ & 40.6 & 19.6 & .0001 \\
\hline $60-74$ & 50.0 & 49.3 & \\
\hline$\geq 75$ & 9.4 & 31.2 & \\
\hline Female gender & 18.2 & 32.7 & .0001 \\
\hline Diabetes & 36.3 & 40.6 & .18 \\
\hline Renal failure & 1.7 & 6.8 & .0002 \\
\hline Hypertension & 63.7 & 65.5 & .56 \\
\hline Hypercholesterolemia & 86.8 & 79.5 & .003 \\
\hline PVD & 12.4 & 18.3 & .015 \\
\hline CVD & 8.2 & 17.9 & .0001 \\
\hline COPD & 10.7 & 18.3 & .001 \\
\hline Previous CABG & 5.2 & 2.8 & .05 \\
\hline $\mathrm{EF}<40$ & 9.0 & 16.0 & .001 \\
\hline \multicolumn{4}{|l|}{ NYHA class } \\
\hline I & 2.0 & 1.1 & .003 \\
\hline II & 14.2 & 9.4 & \\
\hline III & 45.3 & 39.5 & \\
\hline IV & 38.6 & 50.0 & \\
\hline \multicolumn{4}{|l|}{ Status } \\
\hline Elective & 61.0 & 45.8 & .0001 \\
\hline Inhouse & 33.1 & 45.4 & \\
\hline Urgent $<24$ hours & 5.0 & 7.0 & \\
\hline Emergency & 1.0 & 1.8 & \\
\hline \multicolumn{4}{|l|}{ Distal anastomosis } \\
\hline 2 & 8.2 & 16.6 & .0001 \\
\hline 3 & 50.5 & 38.9 & \\
\hline 4 & 32.8 & 31.9 & \\
\hline$\geq 5$ & 8.5 & 12.6 & \\
\hline Off-pump & 9.7 & 10.7 & .62 \\
\hline
\end{tabular}

$\overline{L I T A \text {, Left internal thoracic artery; } S V \text {, saphenous vein; } P V D \text {, peripheral }}$ vascular disease; $C V D$, cerebrovascular disease; $C O P D$, chronic lung disease; $C A B G$, coronary artery bypass grafting; $E F$, ejection fraction; NYHA, New York Heart Association.

SVG late experience, and time (early $=$ first 18 months or late $=$ last 24 months).

\section{Results}

\section{Patient Characteristics}

A total of 944 consecutive patients who underwent CABG surgery performed by 1 of the 4 surgeons experienced in composite grafts at our center and who met our graft composition criteria were identified between January 1999 to July 2002. Of these, 402 (42.6\%) were composite (no saphenous vein conduits, no proximal anastomoses) and the remaining 542 were CABG controls (left ITA + SVG). Patient characteristics of the 2 groups are listed in Table 1. In summary, composite patients were significantly younger, more often of male gender, with less comorbid diseases, better New York Heart Association (NYHA) class, and less often operated upon urgently. In addition, composite graft patients received more distal anastomoses. The unadjusted
TABLE 2. Patient characteristics of composite arterial grafts versus LITA + SV, in $\mathbf{4 9 8}$ matched cases obtained by greedy matching technique using propensity scores

\begin{tabular}{|c|c|c|c|}
\hline $\begin{array}{l}\text { Preoperative patient } \\
\text { characteristic }\end{array}$ & $\begin{array}{l}\text { Composite Graft } \\
\text { (n = 249), \% }\end{array}$ & $\begin{array}{c}\text { LITA + SV } \\
(n=249), \%\end{array}$ & $P$ value \\
\hline \multicolumn{4}{|l|}{ Age } \\
\hline$<60$ & 29.7 & 26.1 & .62 \\
\hline $60-74$ & 55.0 & 56.6 & \\
\hline$\geq 75$ & 15.3 & 17.3 & \\
\hline Female gender & 21.3 & 23.7 & .52 \\
\hline Diabetes & 37.4 & 39.0 & .71 \\
\hline Renal failure & 2.8 & 2.8 & 1.00 \\
\hline Hypertension & 66.3 & 62.6 & .40 \\
\hline Hypercholesterolemia & 83.9 & 83.5 & .90 \\
\hline PVD & 15.7 & 11.6 & .19 \\
\hline CVD & 12.0 & 12.4 & .89 \\
\hline COPD & 14.9 & 13.2 & .61 \\
\hline Previous CABG & 4.4 & 4.4 & 1.00 \\
\hline $\mathrm{EF}<40$ & 13.2 & 12.0 & .69 \\
\hline \multicolumn{4}{|l|}{ NYHA class } \\
\hline 1 & 1.2 & 2.0 & .71 \\
\hline II & 13.6 & 14.9 & \\
\hline III & 43.4 & 45.8 & \\
\hline IV & 41.8 & 37.4 & \\
\hline \multicolumn{4}{|l|}{ Status } \\
\hline Elective & 55.0 & 57.4 & .75 \\
\hline Inhouse & 38.6 & 34.5 & \\
\hline Urgent $<24$ hours & 5.2 & 6.8 & \\
\hline Emergency & 1.2 & 1.2 & \\
\hline \multicolumn{4}{|l|}{ Distal anastomosis } \\
\hline 2 & 11.6 & 9.2 & .85 \\
\hline 3 & 45.4 & 46.6 & \\
\hline 4 & 32.1 & 32.5 & \\
\hline$\geq 5$ & 10.8 & 11.6 & \\
\hline Off-pump & 8.0 & 8.8 & .75 \\
\hline
\end{tabular}

LITA, Left internal thoracic artery; $S V$, saphenous vein; $P V D$, peripheral vascular disease; $C V D$, cerebrovascular disease; $C O P D$, chronic lung disease; $C A B G$, coronary artery bypass grafting; $E F$, ejection fraction; NYHA, New York Heart Association.

in-hospital mortality for the composite group was $1 \%$ and for the control group was $2.8 \%(P=.06)$.

\section{Comparison Using Propensity Score Analysis}

The propensity score model included 24 patient variables that are listed along with their confidence intervals in Appendix. The c-statistic for this model was 0.80 (HosmerLemeshow goodness-of-fit $P=.3057$ ). Two hundred fortynine of 402 composite cases (62\%) could be matched to controls. The 2 groups were well matched for all the patient variables (Table 2). The number of grafted vessels was 3.4 \pm 0.9 grafts in the composite group compared to $3.5 \pm 0.9$ grafts in the matched group $(P=.28)$. The conduits utilized in the composite group were the left ITA $(98 \%)$, the right ITA (19\%), and radial artery (89\%). The conduits utilized in the matched group were the left ITA (100\%) and SVGs. The CPB time (128 vs 105 minutes; $P<.0001)$ and clamp time 
TABLE 3. Perioperative outcomes for composite arterial grafts versus LITA + SV, in $\mathbf{4 9 8}$ matched cases obtained by greedy matching technique using propensity scores

\begin{tabular}{|c|c|c|c|}
\hline Perioperative outcome & $\begin{array}{l}\text { Composite } \\
\text { graft } \\
(n=249) \\
n(\%)\end{array}$ & $\begin{array}{l}\text { LITA + SV } \\
\text { (n = 249) } \\
\text { n (\%) }\end{array}$ & $P$ value \\
\hline $\begin{array}{l}\text { Combined outcome: } \\
\text { (Mort/IABP/MI/Stroke/ } \\
\text { LongVent) }\end{array}$ & $34(13.6)$ & $16(6.4)$ & .007 \\
\hline In-hospital mortality & $3(1.2)$ & $1(0.4)$ & .62 \\
\hline Intra-/postop IABP & $9(3.6)$ & $2(0.8)$ & .06 \\
\hline Periop MI & $7(2.8)$ & $4(1.6)$ & .54 \\
\hline Stroke & $6(2.4)$ & $2(0.8)$ & .29 \\
\hline $\begin{array}{l}\text { Prolonged ventilation }> \\
24 \text { hours }\end{array}$ & $32(12.8)$ & $12(4.8)$ & .002 \\
\hline Deep sternal infection & $3(1.2)$ & $2(0.8)$ & $<1.00$ \\
\hline Blood products & $48(19.3)$ & $39(15.7)$ & .29 \\
\hline Inotropes leaving OR & $53(21.3)$ & $49(19.7)$ & .66 \\
\hline Return to OR for bleeding & $4(1.6)$ & $5(2.0)$ & $<1.00$ \\
\hline $\begin{array}{l}\text { Return to OR for graft } \\
\text { occlusion }\end{array}$ & $4(1.6)$ & $0(0.0)$ & .12 \\
\hline $\begin{array}{l}\text { Number of grafts/patients } \\
\text { (mean, SD) }\end{array}$ & $3.4 \pm 0.9$ & $3.5 \pm 0.9$ & \\
\hline $\begin{array}{l}\text { Pump time, minutes } \\
\text { (median, IOR) }\end{array}$ & $128(102-160)$ & $105(86-133)$ & .0001 \\
\hline $\begin{array}{l}\text { Clamp time, minutes } \\
\text { (median, IQR) }\end{array}$ & $102(78-132)$ & $74(59-94)$ & .0001 \\
\hline $\begin{array}{l}\text { Postop stay, days } \\
\text { (median, IQR) for } \\
\text { patients alive at } \\
\text { discharge }\end{array}$ & $6(5-8)$ & $6(5-8)$ & .11 \\
\hline
\end{tabular}

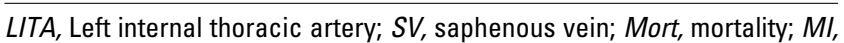
myocardial infarction; LongVent, prolonged ventilation; $I A B P$, intra-aortic balloon counterpulsation; $O R$, operating room; $I Q R$, interquartile range.

(102 vs 74 minutes; $P<.0001$ ) were significantly longer for the composite group compared with matched patients (Table 3).

The mortality was $1.2 \%$ in the composite group and $0.4 \%$ in the matched group $(P=.62)$. The length of hospitalization was a median of 6 days in both groups with an interquartile range of 5 to 8 days $(P=.11)$. Major morbidity was not statistically different between composite and matched groups in terms of: intra/postoperative IABP $(3.6 \%$ vs $0.8 \% ; P=.06)$, postoperative MI $(2.8 \%$ vs $1.6 \% ; P<$ $.54)$, permanent stroke ( $2.4 \%$ vs $0.8 \% ; P=.29$ ), and rates of deep sternal wound infection $(1.2 \%$ vs $0.8 \% ; P=1.00)$ (Table 3$)$. However, significantly more patients in the composite group required prolonged mechanical ventilation compared with matched patients $(12.8 \%$ vs $4.8 \%$; $P=$ .002). The combined outcome of death, IABP, MI, stroke, and prolonged ventilation was also significantly higher in the composite group compared with matched patients $(13.6 \%$ vs $6.4 \% ; P=.007)$.
TABLE 4. Patient characteristics of composite arterial grafts greedy matched $(n=249)$ versus failed to match ( = 153)

\begin{tabular}{|c|c|c|c|}
\hline $\begin{array}{l}\text { Preoperative patient } \\
\text { characteristic }\end{array}$ & $\begin{array}{c}\text { Composite graft } \\
\text { greedy matched } \\
\text { (n = 249), \% }\end{array}$ & $\begin{array}{l}\text { Composite graft } \\
\text { failed to match } \\
\text { (n = 153), \% }\end{array}$ & $P$ value \\
\hline \multicolumn{4}{|l|}{ Age } \\
\hline$<60$ & 29.7 & 58.2 & .0001 \\
\hline $60-74$ & 55.0 & 41.8 & \\
\hline$\geq 75$ & 15.3 & 0.0 & \\
\hline Female gender & 21.3 & 13.1 & .04 \\
\hline Diabetes & 37.4 & 34.6 & .58 \\
\hline Renal failure & 2.8 & 0.0 & .05 \\
\hline Hypertension & 66.3 & 59.5 & .17 \\
\hline Hypercholesterolemia & 83.9 & 91.5 & .03 \\
\hline PVD & 15.7 & 7.2 & .01 \\
\hline CVD & 12.0 & 2.0 & .0003 \\
\hline COPD & 14.9 & 3.9 & .0006 \\
\hline Previous CABG & 4.4 & 6.5 & .35 \\
\hline $\mathrm{EF}<40$ & 13.2 & 2.0 & .0001 \\
\hline \multicolumn{4}{|l|}{ NYHA class } \\
\hline 1 & 1.2 & 3.3 & .22 \\
\hline II & 13.6 & 15.0 & \\
\hline III & 43.4 & 48.4 & \\
\hline IV & 41.8 & 33.3 & \\
\hline \multicolumn{4}{|l|}{ Status } \\
\hline Elective & 55.0 & 70.6 & .01 \\
\hline Inhouse & 38.6 & 24.2 & \\
\hline $\begin{array}{l}\text { Urgent }<24 \\
\text { hours }\end{array}$ & 5.2 & 4.6 & \\
\hline Emergency & 1.2 & 0.6 & \\
\hline \multicolumn{4}{|l|}{ Distal anastomosis } \\
\hline 2 & 11.6 & 2.6 & .0003 \\
\hline 3 & 45.4 & 58.8 & \\
\hline 4 & 32.1 & 34.0 & \\
\hline$\geq 5$ & 10.8 & 4.6 & \\
\hline Off-pump & 8.0 & 12.4 & .15 \\
\hline
\end{tabular}

$P V D$, Peripheral vascular disease; $C V D$, cerebrovascular disease; COPD, chronic lung disease; $C A B G$, coronary artery bypass grafting; $E F$, ejection fraction; NYHA, New York Heart Association.

The 153 composite patients that failed to match from the composite group are illustrated in Table 4. In summary, patients who failed to match were significantly younger, more often of male gender, with less comorbid diseases, normal ventricular function, and performed less urgently than the cohort that we were able to match to controls.

\section{Comparison Using Multivariable Analysis}

A multiple logistic regression analysis was performed on the entire cohort of 944 patients. The outcome evaluated was a combined outcome of mortality and morbidity because of the low event rate associated with individual variables. The combined outcome ( $\mathrm{n}=105$ events) included: death, intra/post-IABP utilization, postoperative MI, permanent stroke, and prolonged mechanical ventilation $(>24$ 
TABLE 5. Multivariable preoperative predictors of combined outcome (Mortality/IABP/MI/Stroke/Prolonged Ventilation); combined outcome occurred in 105 of 944 cases

\begin{tabular}{lcc}
\hline Variable & Odds ratio & Range \\
\hline EF $<40$ & 3.6 & $2.0-6.6$ \\
COPD & 2.6 & $1.5-4.7$ \\
Urgent & 2.5 & $1.2-4.9$ \\
CVD & 2.3 & $1.3-4.4$ \\
Composite graft & 2.1 & $1.2-3.7$ \\
PVD & 2.0 & $1.2-3.5$ \\
NYHA class IV & 1.8 & $1.1-3.0$
\end{tabular}

$E F$, Ejection fraction; COPD, chronic lung disease; $C V D$, cerebrovascular disease; $P V D$, peripheral vascular disease; NYHA, New York Heart Association.

hours). A c-statistic was calculated as a measure of the sensitivity and specificity of the logistic regression model and was 0.81 . In the fully adjusted model, 7 independent predictors of the combined morbidity outcome were identified (Table 5). Composite arterial grafting was found to be an independent predictor of the combined mortality/morbidity outcome with an odds ratio of 2.1 (1.2-3.7). The other independent predictors for the combined outcome were: ejection fraction less than $40 \%$, chronic lung disease (COPD), urgent surgery, cerebrovascular disease (CVD), peripheral vascular disease (PVD) and NYHA class IV.

Because composite grafting is technically demanding and may be subject to a surgical learning curve, we created a second logistic regression model that included time and experience variables defined as: composite early experience, ITA + SVG early experience, composite late experience, ITA + SVG late experience, and time (early or late). Using this approach early composite grafting experience remained an independent predictor of the combined morbidity outcome (death, IABP, MI, stroke, and prolonged ventilation) with an odds ratio of 4.1 (2.0-8.4). The cstatistic for this model was 0.82 .

\section{Reinterventions}

Four patients in the composite group had postoperative angiograms because of evidence of recurrent myocardial ischemia (day 0 to day 10). In 3 of these patients there was stenosis at the composite anastomosis, while in the fourth patient (redo CABG in the setting of a patent left ITA) angiography demonstrated an unrecognized injury to the old left ITA graft. All 4 patients were regrafted and eventually discharged home in good condition. No patients in the matched group were reoperated upon for graft failure.

\section{Discussion}

Arterial grafting has increasingly been advocated for the treatment of coronary artery disease in an attempt to im- prove the long-term results. ${ }^{7-11}$ In support of the safety of arterial grafting, multiple retrospective case series have been published with excellent outcomes. ${ }^{7-11}$ Lytle and colleagues, ${ }^{5}$ in a large retrospective review of 10,124 patients comparing risk-adjusted outcomes of patients who received 2 ITA grafts with patients receiving only 1 ITA graft, reported single ITA grafting was an independent predictor of death and reintervention. Recently a case-matched study comparing saphenous vein graft $(n=956)$ to radial artery graft $(n=478)$ showed an improved freedom from reintervention up to 36 months in radial artery conduit patients. ${ }^{12}$ Composite arterial grafting, in which a free arterial graft is anastomosed to the side of a pedicled ITA graft (usually left), is also gaining in popularity. This approach facilitates complete arterial grafting and limits manipulation of the aorta normally associated with performing proximal anastomoses. $^{7-9}$ Recent case series attest to the safety of this approach, but to date a comparative study has not been carried out. ${ }^{7-11}$ In fact, variations in patient selections for total arterial grafting, choice of arterial conduit, and the use of composite arterial grafts have made comparison to established techniques of ITA grafts and SVGs problematic.

We report our experience with total arterial grafting employing composite arterial grafting using either 2 ITAs or 1 ITA and radial artery compared with control patients having CABG surgery performed with left ITA and SVGs. The overall mortality in the composite group of $1 \%$ compared favorably to other series. ${ }^{7-11}$ We have attempted to make meaningful comparisons between the composite group and a contemporaneous set of left ITA vein graft control cases operated upon by the same surgeons. To do this we have employed 2 statistical approaches based on propensity modeling, a technique that has been strongly advocated in several recent publications, in an effort to better evaluate treatment comparisons from nonrandomized clinical experiences. ${ }^{14,15}$ The propensity score is the probability of a patient receiving a given intervention (in this case composite arterial grafting) based on a nonparsimonious model derived from preoperative patient variables. The propensity model thus reduces many variables to a single balancing score, facilitating meaningful intergroup comparisons. We utilized 2 approaches, namely the creation of matched pairs based on propensity score and logistic regression analysis of outcomes in which propensity score participated as a variable.

Case matching based on propensity score is superior to conventional case matching, which typically utilizes a smaller set of variables for matching. ${ }^{13-16}$ Using this technique the composite arterial and control groups were remarkably well matched in terms of known risk predictors of outcomes following CABG surgery. The overall mortality and major morbidity between groups were not statistically 
different. However, requirement for prolonged mechanical ventilation for more than 24 hours was significantly higher in the composite group compared with matched patients. Prolonged mechanical ventilation, defined as greater than 24 hours in this study, has previously been demonstrated to be a reliable surrogate marker for increased overall morbidity and mortality following CABG surgery. ${ }^{17-19}$ However, a potential explanation for this observation may be the significantly longer $\mathrm{CPB}$ and clamp times used in patients undergoing composite grafts.

In addition, a combined mortality and morbidity outcome was generated in an attempt to address the low event rate and the small sample size of our analysis while maintaining clinical relevance. The choice of the variables in this combined outcome was based on their clinical association with poor patient outcome following CABG surgery. ${ }^{17}$ Composite arterial grafting was shown to be significantly associated with the combined outcome compared with matched patients. It is important to note that we were unable to match 153 composite arterial cases (38\%). When we examined the patient characteristics of the unmatched composite cases in comparison with the 249 composite arterial cases we were able to match, the unmatched cases were significantly lower risk than their matched counterparts (younger, more often male, fewer incidences of ejection fraction $<40 \%$, less PVD, CVD, COPD, and less often urgent). Thus our casematched result is likely to be more representative of the higher-risk subset of our composite arterial group, but alternatively the adverse effects of composite grafting may also be overestimated by the matching strategy.

To allow meaningful comparisons with the entire cohort of 944 patients, we utilized a multiple logistic regression analysis using the previously defined combined morbidity/ mortality outcome. Using this analysis, composite arterial grafting was found to be an independent predictor of our combined morbidity/mortality outcome (mortality/IABP/ $\mathrm{MI} / \mathrm{stroke} /$ prolonged vent) with an odds ratio of 2.1 (95\% confidence interval 1.2-3.7). Because of the technically demanding nature of composite arterial grafting, we employed a second logistic regression model to look for a learning curve effect. Additional time and experience variables were added to the model and included early composite graft (first 18 months) and late composite graft (final 24 months) experiences. In this final analysis, early composite graft experience was found to be an independent predictor of adverse outcomes as compared with other grafting strategies. This finding suggests that there is a significant learning curve effect related to technical competence impacting outcomes of composite arterial grafting. Alternatively patient selection may have improved with increasing experience with the technique.

Taken together, these data indicate that composite grafts were independently associated with increased patient mor- bidity (prolonged ventilation) and a combined end point of mortality and major morbidity. Our observations may be the result of inadequate flow reserve in a single ITA or due to technical error resulting in compromised flow in 1 or both limbs of the composite graft. Indeed, 4 patients in the composite arterial group returned to the operating room for graft revision while none of the control group underwent graft revision. One must bear in mind that a number of case series provide evidence that the angiographic patency and flow capacity of composite grafts are good, with good shortand medium-term results. ${ }^{8-10,20,21}$ The outcome difference between composite arterial cases and controls may be related to longer pump and clamp times in the composite group, reflecting increased technical difficulty of exclusive arterial anastomoses. It may be advisable to alter our strategy and perform the composite anastomosis at the beginning of the operation prior to initiating CPB. This strategy could significantly shorten aortic clamp times and pump times and allow evaluation of flow in both limbs of the composite graft prior to distal anastomosis.

In summary, our findings raise some concerns about the routine use of composite arterial grafting. However, one must be cautious in interpreting our findings as our analysis was limited by its retrospective design and relatively small sample size. Another limitation of our analysis was the use of a combined outcome where 1 variable (prolonged ventilation) was already shown to be significantly different between groups, potentially disproportionally influencing the combined outcome. Nevertheless, there are several factors involved in the choice of conduits for CABG patients made by surgeons, some of which may not be included among the patient variables available for adjustment. The lack of mortality difference between the groups provides some reassurance that the differences in the incidence of prolonged ventilation and combined outcome were perhaps in part discretionary on the part of caregiver's awareness of the composite arterial technique employed and the prolonged perfusion times. Our observations support the need for a prospective, multi-institutional study to better determine both the short- and long-term outcomes of exclusive arterial grafting as alluded to by a recent small randomized trial indicating that short-term result following composite grafting resulted in improved freedom from adverse cardiac events when compared with conventional ITA and SVG grafting. ${ }^{22}$

\section{References}

1. Detre KM, Guo P, Holubkov R, Califf RM, Sopko G, Bach R, et al. Coronary revascularization in diabetic patients. A comparison of the randomized and observational components of the Bypass Angioplasty Revascularization Investigation (BARI). Circulation. 1999;99:633-40.

2. Fitzgibbon GM, Kafka HP, Leach AJ, Keon WJ, Hooper GD, Burton JR. Coronary bypass graft fate and patient outcome: angiographic follow-up of 5065 grafts related to survival and reoperation in 1388 patients during 25 years. J Am Coll Cardiol. 1996;28:616-26. 
3. Bourassa MG, Fisher LD, Campeau L, Gillespie MJ, McConney M, Lesperance J. Long-term fate of bypass grafts: the coronary artery surgery study (CASS) and Montreal Heart Institute experiences. Circulation. 1985;72:V71-8.

4. Cameron A, Davis KB, Green G, Schaff HV. Coronary bypass surgery with internal-thoracic-artery grafts: effects on survival over a 15-year period. N Engl J Med. 1996;334:216-9.

5. Lytle BW, Blackstone EH, Loop FD, Houghtaling PL, Arnold JH, Akhrass R, et al. Two internal thoracic artery grafts are better than one. J Thorac Cardiovasc Surg. 1999;117:855-72.

6. Loop FD, Lytle BW, Cosgrove DM, et al. Influence of the internal mammary artery graft on 10 year survival and other cardiac events. N Engl J Med. 1986;314:1-6.

7. Tector AJ, McDonald ML, Kress DC, Downey FX, Schmahl TM. Purely internal thoracic artery grafts: outcomes. Ann Thorac Surg. 2001;72:450-5.

8. Calafiore AM, Contini M, Vitolla G, Di Mauro M, Mazzei V, Teodori $\mathrm{G}$, et al. Bilateral internal thoracic artery grafting: long-term clinical and angiographic results of in situ versus Y grafts. J Thorac Cardiovasc Surg. 2000;120:990-8.

9. Taloutis J, Buxton BF, Fuller JA, Royse AG. Total arterial coronary revascularization: techniques and results in 3220 patients. Ann Thorac Surg. 1999;68:2093-9.

10. Weinschelbaum EE, Gabe ED, Macchia A, Smimmo R, Saurez LD. Total myocardial revascularization with arterial conduits: radial artery combined with internal thoracic arteries. J Thorac Cardiovasc Surg. 1997;114:911-6.

11. Wendler O, Hennen B, Demertzis S, Markwirth T, Tscholl D, Lausberg $\mathrm{H}$, et al. Complete arterial revascularization in multivessel coronary artery disease with 2 conduits (skeletonized grafts and T grafts). Circulation. 2000;102(Suppl III):III79-83.

12. Cohen G, Tamariz MG, Sever JY, Liaghati N, Guru V, Christakis GT, et al. The radial artery versus the saphenous vein graft in contemporary CABG: a case matched study. Ann Thorac Surg. 2001;71:180-6.

13. Parsons LS. Reducing bias in a propensity score matched-pair sample using greedy matching techniques. Proceedings of the Twenty-sixth Annual SAS Users group international conference 2001, SAS Institute Inc, Cary (NC), April 22-25, 2001.

14. Blackstone EH. Breaking down barriers: helpful breakthrough statistical methods you need to understand better. J Thorac Cardiovasc Surg. 2001;122:430-9.

15. Blackstone EH. Comparing apples and oranges. J Thorac Cardiovasc Surg. 2002;123:8-15.

16. Norman S, Landrum B, Guadagnoli E, et al. Validating recommendations for coronary angiography following acute myocardial infarction in the elderly: a matched analysis using propensity scores. J Clin Epidemiol. 2001;54:387-98.

17. Baskett RJ, Buth KJ, Legare JF, Hassan A, Friesen CH, Hirsch GM, et al. Is it safe to train residents to perform cardiac surgery? Ann Thorac Surg. 2002;74:1043-8.

18. Legare JF, Hirsch GM, Buth KJ, MacDougall C, Sullivan JA. Preoperative prediction of prolonged mechanical ventilation following coronary artery bypass grafting. Eur J Cardiothorac Surg. 2001;20:930-6.

19. Force T, Hibberd P, Weeks G, Kemper AJ, Bloomfield P, Tow D, et al. Perioperative myocardial infarction after coronary artery bypass surgery. Clinical significance and approach to risk stratification. Circulation. 1990;82:903-12.

20. Ochi M, Hatori N, Bessho R, Fujii M, Saji Y, Tanaka S, et al. Adequacy of flow capacity of bilateral internal thoracic artery $\mathrm{T}$ graft. Ann Thorac Surg. 2001;72:2008-12.
21. Royse AG, Royse CF, Groves KL, Yu G. Blood flow in composite arterial grafts and effect of native coronary flow. Ann Thorac Surg. 1999;68:1619-22.

22. Muneretto C, Negri A, Manfredi J, Terrini A, Radella G, Elquarra S, et al. Safety and usefulness of composite grafts for total arterial myocardial revascularization: a prospective randomized evaluation. J Thorac Cardiovasc Surg. 2003;125:826-35.

\section{APPENDIX}

Logistic regression model to generate propensity scores for composite graft $(n=402)$ vs lima + sv graft $(542)$ : the logistic procedure, odds ratio estimates

\begin{tabular}{lcccc}
\hline & & \multicolumn{3}{c}{$\begin{array}{c}95 \% \text { Wald } \\
\text { confidence } \\
\text { limits }\end{array}$} \\
Effect & Point estimate & \multicolumn{2}{c}{$\boldsymbol{P}$ value } \\
\hline OPCAB & 0.594 & 0.343 & 1.030 & .06 \\
>4 distals & 2.119 & 1.082 & 4.150 & .03 \\
4 distals & 3.792 & 2.209 & 6.512 & $<.001$ \\
3 distals & 4.580 & 2.737 & 7.666 & $<.001$ \\
Emergency & 1.476 & 0.337 & 6.470 & .61 \\
Urgent & 0.608 & 0.302 & 1.226 & .16 \\
In-house & 0.636 & 0.450 & 0.900 & .01 \\
NYHA class & & & & \\
$\quad$ IV & 0.631 & 0.187 & 2.127 & .46 \\
$\quad$ III & 0.737 & 0.222 & 2.450 & .62 \\
$\quad$ II & 0.682 & 0.194 & 2.388 & .55 \\
Surgeon 3 & 0.155 & 0.092 & 0.260 & $<.001$ \\
Surgeon 2 & 0.320 & 0.210 & 0.488 & $<.001$ \\
Surgeon 1 & 0.928 & 0.561 & 1.536 & .77 \\
Age >74 & 0.135 & 0.081 & 0.225 & $<.001$ \\
Age 60-74 & 0.461 & 0.325 & 0.656 & $<.001$ \\
Sex & 0.591 & 0.409 & 0.855 & .005 \\
Diabetes & 0.785 & 0.571 & 1.078 & .13 \\
CRF & 0.408 & 0.161 & 1.036 & .06 \\
HTN & 1.162 & 0.842 & 1.604 & .36 \\
Hypercholesterolemia & 1.459 & 0.957 & 2.222 & .08 \\
PVD & 0.911 & 0.579 & 1.433 & .69 \\
CVD & 0.454 & 0.279 & 0.740 & .002 \\
COPD & 0.548 & 0.350 & 0.858 & .01 \\
PREVCAB & 1.836 & 0.812 & 4.154 & .14 \\
EF 40 & 0.573 & 0.352 & 0.934 & .03
\end{tabular}

Association of Predicted Probabilities and Observed Responses Pairs $217884 \quad$ c-statistic 0.796

LITA, Left internal thoracic artery; $S V$, saphenous vein; OPCAB, beating heart surgery; NYHA, New York Heart Association; $C R F$, renal insufficiency; $H T N$, hypertension; $P V D$, peripheral vascular disease; $C V D$, cerebrovascular disease; $C O P D$, chronic lung disease; Prevcab, previous surgery; $E F$, ejection fraction. 